\title{
The Application of Art Design based on New Media
}

\author{
Wang Lei, Yu Wenwen, Zhao Guoxiang \\ Zhangjiakou Vocational and Technical College, Hebei, China, 075000
}

Keywords: New media; Art design; Application

\begin{abstract}
New media has gradually infiltrated into various art fields, and art design is inevitably affected. With the improvement of living, people's spiritual needs are increasingly strengthened. People's requirements on art design are gradually changing under the development of new media technology. New media expands the way of information dissemination and constantly enriches the extension of art design. New media technology has extended the thinking mode and visual expression means of art design and creation. New media breaks through the limitation of traditional media and brings broader creative space. This paper describes the relevant information of new media and art design, and then analyzes the application of art design in the new media.
\end{abstract}

\section{Introduction}

Art is the most primitive and basic art form in human society. Before the emergence of language, human beings conveyed their messages through gestures and tree branches, which is the epitome of early art design. When art design consciousness appears, its carrier also is evolving unceasingly. The emergence of new media further enriches the expression of art design. New media provides a broader display space for art design, and promotes the further development. Compared with traditional media, "new media" is a digital media technology based on the Internet. New media is a comprehensive carrier that conveys words, pictures, sounds and images through network. It is more integrated and expressive. New media integrates single and separate information to form more a targeted audio-visual feeling. The main characteristics of new media are virtual, digitalization and platform.

\section{Art design based on new media}

\subsection{The analysis on correlation concept}

\subsubsection{The concept of new media}

New media is a relative concept, it is compared with traditional media. The new media has not eliminated the old media, they are a symbiotic relationship. New media include a variety of media forms, the Internet is a collection of language, text, pictures, animation and other media. New media is a digital media technology based on the Internet. It is a comprehensive carrier of text, pictures, audio and video. New media have richer information, more diversified means and stronger expressive force. 


\subsubsection{The concept of art design}

Art design can be simply understood as design activities based on art. Art design includes two aspects, one is the plan or conception, and the other is the realization. Art design is the creation of visualization through certain aesthetic concepts and expression techniques. The connotation of art design is very rich, including stage design, costume design, advertising design, graphic design and other design methods.

\subsection{The features of art design}

\subsubsection{Linguistic features}

The combination of art design and new media technology will change the language features. Art design integrates the virtual visual language and the interaction of design language. Firstly, new media provides a specific virtual platform for art design. The art design completes the design result with the help of the computer, it pays more attention to the multidimensional nature of the design language. Second, language is interactive. Since new media focus on interaction and the audience's feelings, art design in the new media platform is bound to incorporate more interactive elements.

\subsubsection{Aesthetic characteristics}

In the current new media era, audiences begin to participate in the dissemination of information. New media has broken the traditional time and space barriers, making the flow of information more fluent. In terms of time, new media has realized cross-time display. Many graphic designs are no longer the preserve of the aristocracy. In terms of space, new media has broken the geographical restrictions. New media can see art design works thousands of miles away with some devices. More importantly, the perfect combination of reality and virtual gives the audience a surreal experience.

\subsubsection{Transmission characteristics}

Under the influence of new media, the traditional communication mode has changed. The new media platform makes the audience value personal aesthetic feeling more, and the communication mode changes from static state to dynamic state. Art design is designed to resonate with the audience. So, art design must fully consider the aesthetic needs of the audience. The art design makes the dissemination way increasingly rich.

\subsection{The influence of new media on art design}

\subsubsection{The influence on material collection}

Art design based on traditional media needs to go through a long-term material collection process, such as experiencing life personally, observing in the creative environment and so on. There is a lot of blindness in this approach to material collection. Art design is different from the simple art creation, it often has a certain commercial value. If an advertisement design needs to spend a lot of time to collect materials, it will inevitably lead to the loss of economic benefits. Based on the network technology, the new media era provides a more convenient way to collect materials for art design. It effectively adjusted the contradiction between workload and time. At the same time, new media with a large number of advanced equipment has alleviated the deficiency of traditional methods on recording such as sketching and sketching. For example, cameras and video recorders a lot of scenery, especially some natural landscapes with a short history, which can be reviewed and applied repeatedly in the later period. 


\subsubsection{The influence on design creation}

In the new media era, the dissemination of information has been networked. Images or video can be transmitted through any network terminal regardless of time or space. There are a lot of design hardware and software in computer technology, which can directly affect the level of contemporary art design. At the same time, based on the positioning, ruler, calculation and other tools of various software tools, the art works designed can be guaranteed to be more accurate. The design and creation mode has changed the traditional art design profession and created a series of new art positions, such as illustrator and background designer. In the process of computer design, we can flexibly flip, twist and deform 2D and 3D forms. At the same time, we can timely access to a large number of art design information, and adjust their own style and ideas. Which is conducive to the improvement of art level.

\section{The application of art design based on new media}

\subsection{The application of stage art design based on new media}

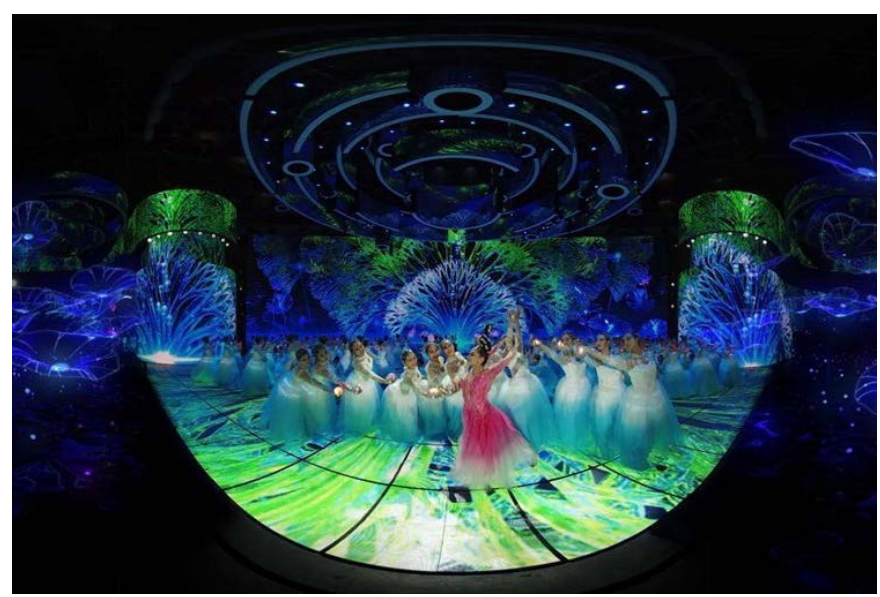

Figure 1 Virtual stage technology

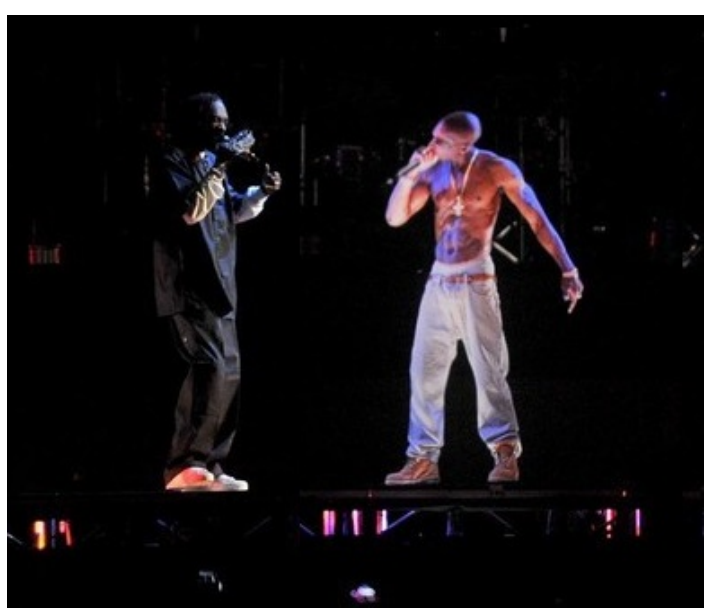

Figure 2 Virtual image holographic projection technology

VR technology is widely used in many fields, such as interior design, geological disaster, tourism landscape and restoration of historic sites. VR technology is also widely used in stage art design. It is used to create an interactive $3 \mathrm{~d}$ environment and make the audience feel immersed. Naked eye 3D giant projection is to project the stage on the opposite large building. By projecting 
the image from the projector onto the facade of the building, a 3D image can be obtained. With the help of existing buildings, this projection technology can create a strong sense of 3D. In museums, exhibition halls and other occasions, it is often necessary to interact with the audience while displaying. Holographic technology can mobilize the emotions of the audience to actively participate in the interaction. Holographic projections project virtual narrators, using electronic sound systems to communicate with the audience. By adding the narrator' shadow to create the space sense, the audience can be greatly drawn in. By communicating with performers, it can effectively increase the power of shock. We can see that the figure 1 is the virtual stage technology and figure 2 is the virtual image holographic projection technology.

\subsection{Dynamic design dominates visual innovation}

In the new media era, visual communication design shows a stronger communication between visual art and people. The accuracy and wonderful performance of fonts can make visual design works more artistic. Font design is the expression of font modeling and skills, making it have innovative aesthetic vision. Dynamic text has a more significant visual expression in new media, which is the combination of new media technology and art. Dynamic text is able to capture the audience's attention more quickly than static text. On the dynamic graphics and images, it is built in four - dimensional space design form. In the design, the designer needs to consider the graphic factors, such as spatial displacement, direction of motion and velocity. We can see that the figure 3 is the Dynamic expression on text design and figure 4 is the Dynamic expression on graphic design.
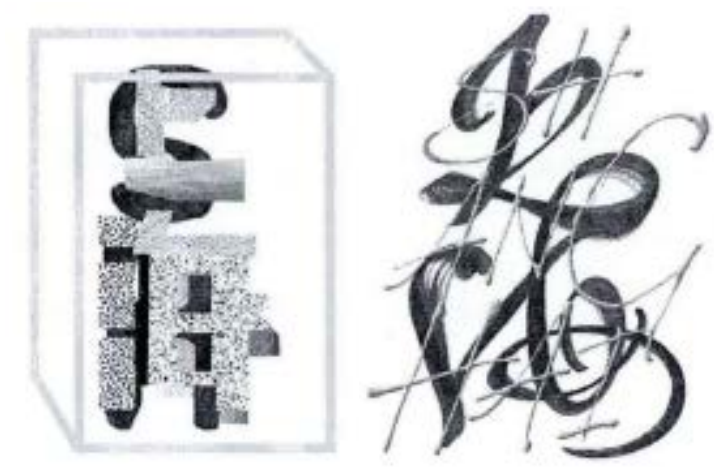

Figure 3: Dynamic expression on text design
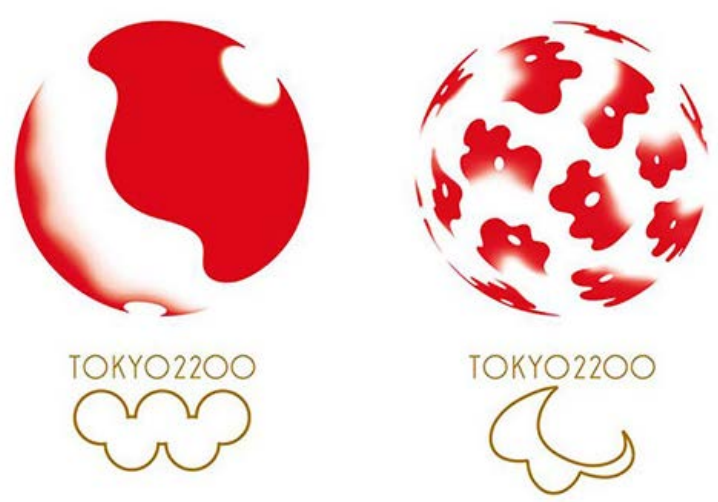

Figure 4: Dynamic expression on graphic design

\section{Conclusions}

New media technology endows visual language and expression form to art design. Information 
transfer has gradually changed from the traditional media to the emerging digital media, and constantly affects the public's lifestyle and aesthetic concept. In the emerging media forms, art design forms become more and more abundant than traditional graphic design. Under the influence of digital and network technology, the concept and thinking mode of art design have changed greatly, and the means of creation have become more convenient and diversified. Graphic design practitioners need to make good use of new media to seek greater breakthroughs in innovation.

\section{References}

[1] Liu Lin, Xu min. Analysis of dynamic logo design forms in the new media environment [J].Theatre house, 2016 (2): 173-174.

[2] Wang zhigang, Zang zhiyun. Analysis on the influence of digital media on visual communication design [J].Journal of jiangsu normal university of technology, 2014 (2): 64-66.

[3] Wang yu. Research on the integration of graphic design and new media in the Internet era [D].Harbin: Harbin normal university, 2016.

[4] Shi xueqing. Research on graphic design under the influence of new media [D]. Shi jia zhuang: Hebei normal university, 2014.

[5] Zheng ya. Visual communication design based on digital media context [J].Design, 2016 (11): 66-67. 